\title{
Normalización del modelo neoliberal de expansión residencial más allá del límite urbano en Chile y España
}

Víctor Jiménez. Universidad de Extremadura, Cáceres, España.

Rodrigo Hidalgo. Pontificia Universidad Católica de Chile, Santiago, Chile. Antonio-José Campesino. Universidad de Extremadura, Cáceres, España.

Voltaire Alvarado. Pontificia Universidad Católica de Chile, Santiago, Chile.

RESUMEN | El crecimiento urbano contemporáneo adopta patrones fragmentados y escasamente densos. El proceso se ha tomado como norma general dentro de un modelo de Estado neoliberal, que lejos de restringir la expansión de lo urbano por ocupación del espacio rural, lo fomenta desregulando el uso del suelo no urbanizable. La ratificación de la participación estatal en la construcción de este fenómeno requiere el análisis de las herramientas que lo posibilitan. Así, utilizar una metodología que incluya el examen y comparación de cuerpos normativos se hace ineludible para revelar el grado de colaboración administrativa que, por acción u omisión, sustenta la producción de espacio residencial. Por lo tanto, el objetivo del presente estudio es corroborar la tendencia generalizada hacia la normativización de la ciudad difusa, que hoy se encuentra ampliamente respaldada en Chile, afianzado un estadio avanzado del proceso hacia el que España transita.

PALABRAS CLAVE | expansión urbana, planificación urbana, relación campo-ciudad.

ABSTRACT | Contemporary urban growth adopts fragmented and sparsely dense patterns. The process has been taken as a general rule within a neoliberal state model, which, far from restricting the expansion of the urban by occupation of the rural space, promotes it by deregulating the use of undeveloped land. The ratification of state participation in the construction of this phenomenon requires the analysis of the tools that make it possible. Thus, using a methodology that includes the examination and comparison of normative bodies becomes inescapable to reveal the degree of administrative collaboration that, by action or omission, supports the production of residential space. Therefore, the objective of this study is to corroborate the generalized tendency towards the normalization of the diffuse city, which today is widely supported in Chile, reinforcing an advanced stage of a process which Spain is beginning to experience.

KEYWORDS | urban sprawl, urban planning, countryside-city relationship. 


\section{Introducción}

Los procesos de acumulación y sobreacumulación del capital impuestos por el modelo neoliberal, bien digeridos por algunas sociedades como la chilena o la espańola, han desligado el crecimiento urbano de los parámetros tradicionales que lo justificaban, ya sean aquellos que atienden a cuestiones espaciales, o bien los relacionados con razones socioeconómicas.

La praxis urbanística se ha desvinculado de su función social para convertirse en un pilar de la economía. Esto ha ocurrido de manera explícita en determinados periodos temporales, como durante el cambio de siglo en Espańa. Siguiendo las ideas de Lefebvre (1968) sobre la aplicación dentro de lo urbano de los conceptos marxistas de valor de uso y valor de cambio, el paradigma social y funcional de la ciudad ha sido reemplazado por uno con tintes economicistas propio de una sociedad posmoderna. La ciudad ya no se crea bajo estándares sostenibles argumentados, sino que se produce y reproduce espacial y temporalmente. La concepción de ciudad como un producto permite replicar el modelo globalmente, como si de un bien producido en cadena se tratase, por lo que se homogeniza y tiende a un patrón único: la ciudad genérica (Koolhaas, 2006).

Este sistema, ya ubicuo, dominado por el poder de clase, requiere la connivencia de los Estados. En la actualidad, las administraciones centrales siguen una tendencia hacia el empequeñecimiento y el descuido de su responsabilidad social, especialmente en los países de América Latina cuyas políticas urbanas tienen un marcado corte neoliberal (Campesino, 2003). La estabilidad del sistema neoliberal requiere también la complicidad de la sociedad, particularmente la clase media, que en última instancia es la base de la estructura debido a su capacidad de compra o endeudamiento. Dentro del recorrido exitoso del neoliberalismo, juega un papel fundamental la "construcción del consentimiento" expuesta por Harvey (2007). Como explica el geógrafo británico, esta "aceptación” del modelo se puede alcanzar por dos vías: la del sometimiento a un régimen dictatorial, como en Chile, o mediante la deformación de un sistema democrático que presenta la justicia social y las libertades individuales como objetivos incompatibles, en el caso de Espańa. El resultado es conocido por todos: los ciudadanos, hoy convertidos en propietarios/consumidores, aceptaron este trueque en pos del prometido desarrollo socioeconómico.

La interiorización de este ideario ha creado una demanda generalizada de bienes raíces y el surgimiento de una potente industria que la alimenta. La participación del grueso de la población en este modelo se ha vehiculado a través de la adquisición de vivienda en propiedad, establecida como símbolo del ascenso social. Por ejemplo, la vivienda propia es el régimen de tenencia dominante tanto en Chile (69,6\% según el censo del año 2012) como en España (78,9\% según el censo del año 2011), aunque en ambos ejemplos la propensión es a la baja (72,6\% en Chile para el año 2002 y 82,2\% en España para el año 2001), debido, al menos en el caso español, a la importante pérdida de capacidad adquisitiva de la población por la crisis económica, con importantes repercusiones de índole social como los desahucios (Méndez \& Plaza, 2016). 
El acceso a la vivienda se ha procurado a través del mercado privado, pero también desde los Estados, no solo como servicio social, sino como mantenimiento subvencionado de una demanda dedicada a sostener la oferta. Encontramos la demostración a este hecho en las calidades de la edificación y la localización, generalmente periférica, de la vivienda social. Esta ha quedado relegada a los espacios menos atractivos y desconectados, lo que ha permitido reducir su costo inicial, facilitando el acceso a las rentas medias y bajas, a cambio de aumentar su costo posterior (gastos en commuting), llevando a una segregación socioespacial basada en una desigual accesibilidad a oportunidades (Salazar \& Cox, 2014).

Las administraciones han dotado de legitimidad a estos incrementos de la superficie artificial mediante la inflación del planeamiento (Gaja, 2015), introduciendo en el mercado inmobiliario una ingente cantidad de terrenos mediante la clasificación sobredimensionada de suelo urbano y urbanizable, y a través de procesos lentos pero continuos de flexibilización del suelo no urbanizable (sNU) o los terrenos rurales (en la terminología española y chilena, respectivamente). Como afirma Sabatini (2000), la liberalización del suelo no desencadenó una bajada generalizada de los precios del suelo, sino que, al contrario, inició una escalada de los mismos debido a un mercado inmobiliario especulativo que se reforzó en Chile desde 1979, y que tuvo su máxima expresión en España a partir del año 1998, por efecto de la Ley 6/1998, de 13 de abril, de Régimen del Suelo y Valoraciones (LRSV).

Los gobiernos deben asumir su cuota de responsabilidad, ya que han facilitado el consumo insostenible del territorio, estableciendo "mecanismos de complicidad entre los planeamientos de ordenación ambiental y los urbanísticos para burlar las sentencias judiciales" (Delgado, 2012, p. 139). En la lucha contra esta doctrina generalizada surgió el manifiesto "Por una nueva cultura del territorio" (AA.vv., 2006), en el que geógrafos y otros expertos urbanistas denunciaron, en pleno cenit de la "década prodigiosa" del urbanismo español (Burriel, 2008), los desmanes urbanísticos y sus consecuencias.

Durante los últimos cincuenta años ha existido una expansión sin precedentes de lo urbano, que no se detuvo ni en periodos de crisis de la ciudad, donde este modo de vida crecía por encima de la dimensión física de la ciudad e incluso por oposición a ella. Estos procesos fueron analizados por Berry (1976) y Champion (1989), y definidos bajo el concepto de contraurbanización. Además, el ritmo de crecimiento ha dificultado su gestión y planificación, originando un modelo de ciudad dispersa que convierte la frontera urbano-rural en un espacio difuso, de tal modo que las ideas lefebvrianas de total urbanización de la sociedad cobran mayor vigencia, ya que se presentan de una manera "cuantitativa y cualitativamente diferente de las evoluciones urbanas del pasado" (Costes, 2011, p. 3). Sustancialmente traumático ha resultado este cambio en los modelos de urbanización mediterráneos (Senabre \& Campesino, 2005), caracterizados por su compacidad y la concomitancia espacial entre la urbs (espacio construido) y la civitas (realidad social urbana). En la actualidad se produce una disociación de ambos conceptos que admite una propagación del modo de vida urbano sin que ello suponga un crecimiento de la ciudad, aunque sí de la superficie artificializada. Algunos autores hablan de "urbanismo de la no ciudad" (Piñero et al., 2015) en estrecha relación con lo defendido por Hidalgo, 
Arenas \& Santana (2016) en cuanto a la construcción de espacios urbanos utópicos/ distópicos gracias a la indispensable colaboración de promotoras inmobiliarias dedicadas a la venta de espacios idílicos inventados. En definitiva, la aparición de "no-lugares" (Augé, 1992) de alta rentabilidad y escasa identidad.

Por lo tanto, debemos poner atención a lo manifestado por Capel (2003), ya que la extensión física urbana presenta dos naturalezas: por una parte, el crecimiento artificial necesario (justificado demográficamente); y, por otro lado, la producción superflua de ciudad (alimentada por el mercado inmobiliario).

La aspiración de complementar la vivienda principal con una segunda residencia y la necesaria conectividad entre ambas han multiplicado nuestra huella ecológica. Sin embargo, estas apetencias llevan siglos inculcadas en nuestra idiosincrasia, como así denotan los trabajos de Dematteis (1998) al reseñar que el anhelo por la "vida rural" ya estaba presente en época romana y que durante el medievo se generalizó entre los estratos sociales medios. La literatura científica ha englobado los procesos de expansión urbana en el medio rural bajo el concepto de periurbanización, el cual no implica exclusivamente una nueva forma de ocupar el territorio, sino la aparición de un espacio multifuncional que puede llegar a ser la forma más común de poblamiento (Ravetz, Fertner \& Nielsen, 2013). La fragmentación de la ciudad ha impactado rotundamente sobre el medio rural, aunque presenta diferentes caras según la escala utilizada (Mansilla, 2013; Monclús, 1998), por lo que conviene fraccionar este concepto.

Por un lado, ha tenido lugar una expansión de la ciudad sobre espacios tangenciales o muy próximos al límite urbano, donde los agentes inmobiliarios juegan un papel esencial. En ellos se explicita la tensión entre los usos del suelo y el avance de la ciudad gracias a procesos como la metropolización y la conurbación. Así se construyen las grandes ciudades actualmente: extendiendo su mancha de forma desordenada, pero dirigida, ya sea por cuestiones de viabilidad o atractivo comercial. La ciudad se torna más difusa, diluyendo límites espaciales y levantando fronteras sociales (Nel.lo, 1998), que suponen un reto para la gobernanza de las mismas dentro de un sistema tendente a la planificación supramunicipal. Según Swyngedouw (2004), la "hiperurbanización", junto con la formación de la clase obrera y la generalización de movimientos masivos y recurrentes de población, ha supuesto una de las más profundas reestructuraciones geográficas.

Por otro lado, la expansión urbana ha ocupado espacios rurales, donde la desconexión con el modo de vida urbano y las mejoras socioeconómicas son el principal acicate para la transformación del suelo. La rurbanización o rururbanización presenta, según Sobrino (2003, p. 105), cinco aspectos que la definen: diversificación ocupacional, permanencia de la tenencia de la tierra, desplazamiento de las actividades agropecuarias como sustento familiar, demanda de servicios públicos, y expansión urbana en suelo rural. Ellos suponen la translocación del modo de vida urbano al campo, precisamente aquello de lo que se pretendía huir. Por lo tanto, los urbanitas repiten un modelo conocido, con leves transformaciones tendentes al esponjamiento del tejido urbano. No obstante, la población autóctona tiene también un rol principal, ya que, tras experimentar un ascenso del nivel económico, buscan un asentamiento diferente con mejores condiciones habitacionales, 
pero sin desligarse de su espacio tradicional (Indovina, 1990). La confluencia de ambas demandas, externa e interna, genera un aumento del número de viviendas en el mundo rural que tiene repercusiones sobre el territorio, aunque no siempre positivas: los trasvases demográficos ciudad/campo no han supuesto una solución a la despoblación rural y el envejecimiento, pues parte de los "neorrurales" son personas jubiladas (Weekley, 1988), al menos en el caso espańol.

Partiendo de la comparación de los marcos legales y poniendo énfasis en el análisis de las políticas de liberalización del suelo en Chile y España, el objetivo de este trabajo es demostrar una tendencia generalizada hacia la desregulación dentro del modelo de Estado neoliberal. Se observa una disposición voluntaria de los Estados por rehuir el debate entre ciudad planificada versus ciudad practicada (Delgado, 2004), diluyendo la distancia entre ambas, anulando la gobernanza sobre la urbe de la ciudadanía y dejando a expensas del mercado liberalizado la construcción de nueva ciudad. Colocar en paralelo los sistemas de organización territorial de los dos países nos llevará a constatar cómo los límites de la legalidad difieren entre ambos y, sin embargo, ya sea por acción u omisión de las entidades competentes en materia urbanística, encontramos realidades semejables.

En resumen, este trabajo se organiza en tres partes. En primer lugar, la presente introducción, dedicada a la fundamentación teórica de los procesos contemporáneos de expansión urbana y la justificación del estudio comparado entre Chile y España. Un segundo epígrafe está destinado a conocer las bases de las políticas urbanas de corte neoliberal, que se presenta dividido por países. Por último, unas reflexiones sobre la evolución del modelo neoliberal de expansión urbana, que revelan un diferente grado de instauración de este en Chile y Espańa y los mecanismos empleados por los Estados para lograr su réplica exitosa en espacios distintos y alejados entre sí.

\section{Refrendo normativo de una política dirigida hacia la diáspora residencial}

La herramienta cardinal para ordenar nuestro territorio y desarrollo urbano se encuentra en los instrumentos de planificación general, como ya expuso la Carta de Atenas: "El azar cederá ante la previsión; a la improvisación sucederá el programa" (Le Corbusier \& Sert, 1957).

Los planes constituyen el elemento ejecutivo de una legislación que valida determinadas políticas. Aun siendo el planeamiento urbanístico previo a los sistemas democráticos instaurados en Chile y España, éste nació, en términos generales y teóricos, como documento integral de servicio público destinado al crecimiento armónico de nuestras ciudades, tomando consciencia de la interrelación de éstas con su territorio periférico. Los antecedentes de este sistema concebían la ciudad como un ente aislado, cuya evolución se proveía a través de planes de desarrollo parciales como los Planes de Ensanche nacidos para facilitar el crecimiento urbano más que para ordenar la ciudad (Terán, 1982). Los primeros indicios de planeamiento general en ambos países se vivieron en los años veinte del siglo pasado (Brieva \& Bastias, 1980; Terán, 1996).

La multiplicación de estos instrumentos, aun siendo el medio adecuado para la ordenación urbana, no ha resultado definitoria para alcanzar los objetivos 
planteados. Los vaivenes legislativos han pervertido su cometido al facilitar un modelo de expansión urbana difusa. Tras esta legitimación de la expansión urbana desmedida se encuentran ideologías liberales, presentes en los marcos normativos estatales como el Decreto con Fuerza de Ley (DFL) no 458 de 1975, General de Urbanismo y Construcciones de Chile (LGUC) o, de forma meridiana, la Ley 7/1997, de 14 de abril, de medidas liberalizadoras en materia de suelo y de colegios profesionales, del Gobierno de España, cuyas ideas se afianzarían posteriormente en la LRsV.

La comparación entre ambos países queda entorpecida por un reparto desigual de las competencias urbanísticas. En el caso español resulta más complejo enunciar medidas de repercusión estatal, debido a que la facultad para regular materias urbanísticas está atribuida a las diecisiete Comunidades Autónomas (CC.AA.) desde la promulgación de la Constitución Española de 1978 (artículo 148.3). Por el contrario, el Estado chileno mantiene dicha competencia centralizada, lo que reduce la producción legislativa y las discrepancias entre regiones.

\section{Políticas de consagración de un consumo improductivo del territorio chileno}

La Ley (DFL no 458 de 1975) y Ordenanza (Decreto Supremo no 47 de 1992) General de Urbanismo y Construcciones de Chile (oguc) son los pilares de la regulación urbanística del país, los cuales mantienen su vigencia gracias a numerosas modificaciones (46 y 93 reformas, respectivamente). Especial importancia tienen también las sucesivas Políticas Nacionales de Desarrollo Urbano (PNDU), por cuanto sus conclusiones, aun no siendo vinculantes, se trasladan a los cuerpos legislativos. Las PNDU aprobadas fueron las de 1979, 1985 y 2013, esta última vigente. Uno de los principios generales de la primera fue que el suelo urbano no era un recurso escaso, por lo que, según Trivelli (1981), la política estaba orientada a la regulación automática del crecimiento de las ciudades a partir del mercado libre de la tierra y un rol subsidiario del Estado. Posteriormente, la PNDU de 1985 dio un giro importante al declarar la planificación del desarrollo urbano como función privativa del Estado, pero su derogación mediante la aprobación del Decreto Supremo (Ds) de Vivienda y Urbanismo no 259 supuso una vuelta atrás en el papel que la administración central debía asumir sobre el urbanismo chileno (Torres, 2005). Por último, la actual PNDU retoma, en teoría, la preocupación por la salvaguarda del bien común y la puesta en marcha de un modelo sustentable de expansión urbana que hasta el momento no tiene reflejo en la legislación.

En primer lugar, debemos detenernos en la clasificación del suelo que establece la ley. En Chile se consideran dos situaciones básicas del suelo: las zonas dentro del "límite urbano" (áreas urbanas y de extensión urbana) y terrenos rurales, definidos por negación a las anteriores (Artículo 52 LGUC). Ante un modelo destinado a la regulación del urbanismo desde una óptica mercantilista, se presupone, y de hecho existe, un déficit en cuanto al ordenamiento de las áreas rurales que ha provocado carencias estructurales para alcanzar un desarrollo urbano sostenible (Iturriaga, 2003).

Los instrumentos de planificación territorial y urbanística chilenos siguen una escala jerárquica (tabla 1). De ellos, los únicos con capacidad para realizar una división urbanística del suelo son los Planes Reguladores Intercomunales y Metropolitanos (PRI, PRM) y los Planes Reguladores Comunales (PRC) (y de forma básica, el Límite 
Urbano [LU]), no siendo ninguno de ellos de carácter obligatorio, aunque con excepciones (artículo 47 LGUC). La ausencia de obligatoriedad universal del planeamiento implica la incapacidad para realizar la división básica en todo el territorio nacional y determinar los parámetros mínimos de subdivisión predial. De todos modos, la aprobación de instrumentos de planeamiento urbanístico no garantiza, bajo el modelo chileno, una protección de los valores propios de las áreas rurales, ya que estos no tienen capacidad para realizar subcategorizaciones urbanísticas propias destinadas a proteger valores ambientales y patrimoniales que no estén reconocidos previamente por las leyes sectoriales. Incluso el establecimiento de límites en el planeamiento urbanístico comunal bajo estándares ambientales, como la prohibición de edificar por encima de determinadas cotas de altura, no ha resultado efectivo, por los déficits en la vigilancia del cumplimiento de la normativa. No obstante, se ha mejorado la fiscalización de estos asuntos mediante la inclusión de la obligada aplicación de la Evaluación Ambiental Estratégica a los instrumentos de planificación desde la promulgación de la Ley n 19.300 sobre Bases Generales del Medio Ambiente.

TABLA I Jerarquía de los instrumentos de ordenación territorial y urbanística de Chile

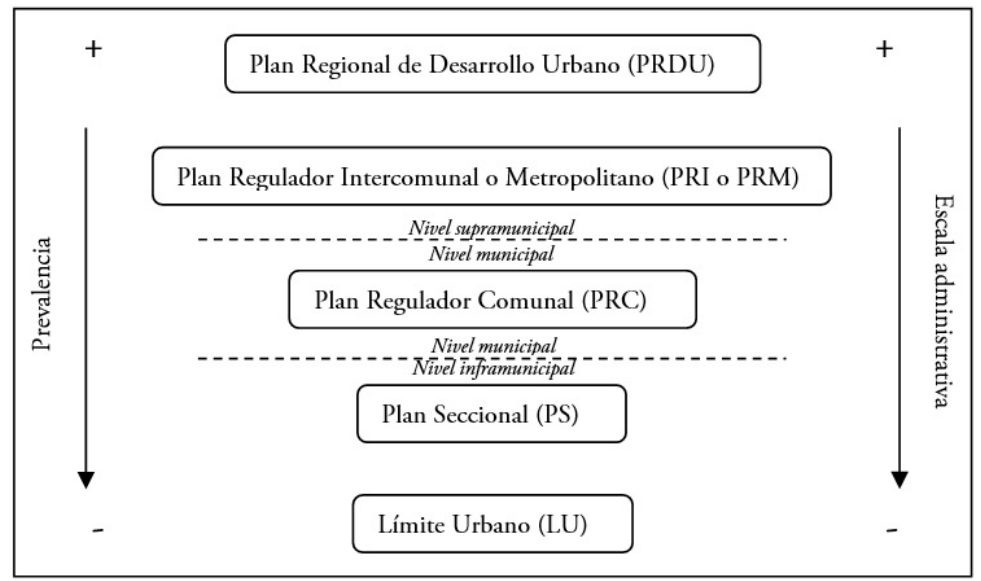

FUENTE DFL N ${ }^{\circ} 458$ DE I 975 , GENERAL DE URBANISMO Y CONSTRUCCIONES DE CHILE. ELABORACIÓN PROPIA

Desde la óptica normativa, tres reformas resultaron esenciales para la instauración en Chile de un modelo de desarrollo urbano disperso.

La primera fue la aprobación del Ds no 420 (1979) para la modificación del Plan Regulador Intercomunal de Santiago de 1960, que contribuyó a la densificación de las áreas urbanas y posibilitó su extensión, lo que se materializó en un aumento de "aproximadamente 60.000 hectáreas, equivalente al 160\% del área urbana” (Vicuña, 2013, p. 4). En la densificación urbana chilena juegan un papel fundamental los condominios, amparados y regulados por la Ley $\mathrm{n}^{\circ} 19.537$ sobre copropiedad inmobiliaria y su reglamento (DS no 46 de 1998), que permite simultáneamente la propiedad compartida sobre los terrenos y la propiedad exclusiva sobre las viviendas. 
La segunda reforma fue la aprobación del Decreto Ley (DL) no 3.516 en 1980, que ha tenido una influencia mayúscula en la colonización residencial de los terrenos rurales (figura 1). Su aprobación incrementó la densidad edificatoria de esta clase de suelo, reduciendo la subdivisión predial mínima de las 20 hectáreas fijadas por el DL $\mathrm{n}^{\circ} 752$, de 1974, hasta las 0,5 hectáreas. Así, el uso residencial establecido por el artículo 55 de la LGUC fue transformado en aprovechamiento urbanístico una vez superados los escollos anecdóticos, como la necesaria vinculación de la vivienda con una explotación agraria. El DL no 3.516, al igual que la LGUC y la OGUC, no define ni el tipo ni el tamaño de la explotación agraria, lo que condujo a la proliferación de viviendas en terreno rural asociadas a raquíticos aprovechamientos agrarios, a menudo ficticios. Se facilitó, por lo tanto, la autopromoción de viviendas para pequeños propietarios, que pertenecían mayoritariamente al nivel socioeconómico medio-alto y alto. Este hecho multiplicó la ocupación residencial de predios rústicos gracias al inferior costo inicial de la vivienda por la localización de las propiedades y su reducido tamaño, las cuales mantenían ventajas comparativas (libertad en la tipología edificatoria y espacio libre propio) a pesar del inherente déficit de servicios que sufrían.

FIGURA I Densificación residencial en el entorno periurbano de Santiago de Chile (Chicureo, 2003-2016)
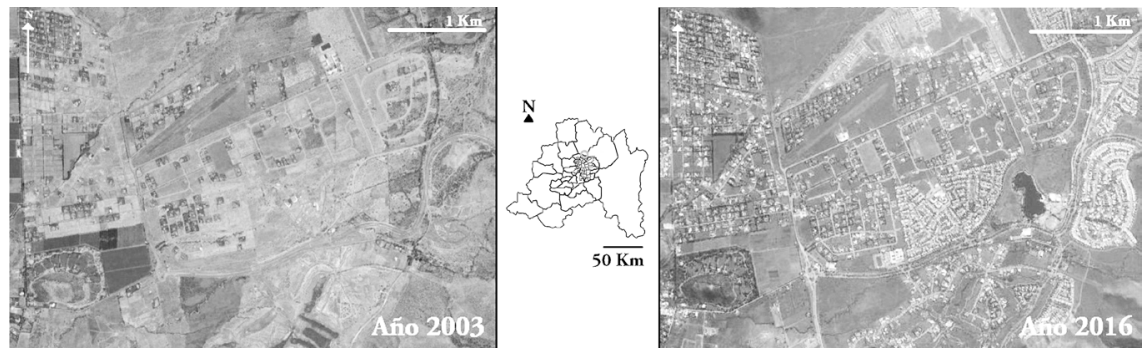

FUENTE ELABORACIÓN PROPIA CON BASE EN NASA IMAGES, GOOGLE EARTH.

Es preciso resaltar que el DL no 3.516 es una norma básica estatal cuyo principal cometido teórico es potenciar y regular la producción agraria minifundista. Sin embargo, parece evidente que detrás de una innovación de la legislación agraria con un cierto halo social se escondía una verdadera transformación del panorama urbanístico. No obstante, el decreto fija parámetros mínimos que pueden ser elevados desde el planeamiento. Justamente, el Plan Regulador Metropolitano de Valparaíso (PRMV) fijó la subdivisión predial mínima en dos hectáreas, mientras que el Plan Regulador Metropolitano de Santiago (PRMS) de 1994 estableció este parámetro para las zonas externas al límite urbano en un mínimo de cuatro hectáreas en algunas comunas y categorías de suelo, lo que no logró atajar la situación, puesto que los propietarios se anticiparon a la iniciativa y subdividieron previamente sus parcelas (Salazar \& Cox, 2014). Además, en el caso de Santiago estas restricciones solo hacen referencia al proceso de parcelación, por lo que sobre los lotes pretéritos ya inscritos en el Conservador de Bienes Raíces, el PRMs ha establecido un aprovechamiento 
urbanístico potencialmente superior en términos relativos, que aumenta a medida que el tamańo de la propiedad disminuye. ${ }^{1}$ Los coeficientes de constructibilidad máxima están establecidos de forma general en el 0,1, lo que implica la edificación de una vivienda principal, que puede ser complementada con otra más destinada a fijar residencia del cuidador de la explotación agraria a la que esté adscrita. De este modo, se ha constituido un sistema de "parcelas agrorresidenciales", como así lo denomina el propio instrumento de planificación, que sirven a un mercado inferior de compraventa de inmuebles (o al uso de la vivienda por allegados o empleados), en la que las residencias auxiliares han servido para sobrepasar de manera sublegal los límites fijados por la norma. Excepcionalmente, la capacidad de estas zonas supuestamente excluidas del aprovechamiento urbanístico se lleva al extremo bajo la premisa de dotar al campesinado de vivienda social, lo que rebaja la superficie mínima del predio edificable hasta los 100 metros cuadrados.

La tercera modificación fue la inclusión en el artículo 55 de la LGUC, mediante la aprobación de la Ley no 19.859 en el año 2003, la posibilidad de construir fuera de los límites urbanos "conjuntos habitacionales de viviendas sociales o de viviendas de hasta un valor de 1.000 unidades de fomento (UF), ${ }^{2}$ que cuenten con los requisitos para obtener el subsidio del Estado". Esto significó la propagación masiva del negocio inmobiliario a un terreno hasta entonces vetado, y lleno de oportunidades en un país con un recurrente déficit habitacional (Henoch \& Horst, 2011; Ministerio de Vivienda y Urbanismo [Minvu], 2004 y 2009). La promoción de la ciudad discontinua se reforzó en la metrópoli de Santiago mediante figuras para el desarrollo urbano como las Zonas de Desarrollo Urbano Condicionado (zoDuc) ${ }^{3}$ y los Proyectos de Desarrollo Urbano Condicionados (PDUC), ${ }^{4}$ estos últimos con capacidad para actuar en el área de Interés Silvo Agropecuario Mixto (ISAM) del PRMS, es decir, el suelo rural. En síntesis, su aprobación constituye una recalificación urbanística bajo una serie de condiciones (superficie total de la actuación no inferior a 300 hectáreas, densidad bruta promedio de 85 habitantes por hectárea, un mínimo del $30 \%$ de viviendas construidas subsidiables y un mínimo del 5\% de

1 El párrafo segundo del artículo 8.1.3. del pRMs establece que en los loteos inscritos en el Conservador de Bienes Raíces de Santiago "se podrá construir una vivienda con una superficie de hasta un $10 \%$ del tamaño del lote. En sitios de superficie inferior a $1.400 \mathrm{~m}^{2}$, esa vivienda podrá llegar hasta $140 \mathrm{~m}^{2}$, siempre y cuando cumpla con las normas contenidas en la OGUC".

2 Según el Ministerio de Hacienda del Gobierno de Chile, la Unidad de Fomento es un "índice que evoluciona de acuerdo a la inflación del mes pasado. Este índice se calcula mensualmente y rige desde el día 10 del mes en curso al día 9 del mes siguiente”. Su correspondencia al 10 de diciembre de 2016 es de 26.330,15 pesos chilenos ( 1 USD = 656,07 CLP, según Banco Central de Chile).

3 Las zoDuc corresponden a áreas continuas o discontinuas respecto de una zona urbana que, en ausencia de vías de acceso o servicios adecuados para una densificación habitacional, pueden desarrollarse bajo el compromiso de generar entornos sostenibles en cuanto a áreas verdes, transporte, educación o servicios primarios de salud.

4 Por su parte, los PDUC hacen referencia a los proyectos habitacionales por producirse dentro de las zoduc. Contemplan una extensión máxima de 300 hectáreas de desarrollo inmobiliario, que puede ser edificado con determinadas condicionantes: vías de acceso, transporte público y servicios en general. En suma, si las anteriores corresponden al polígono, las presentes constituyen el contenido. 
la superficie destinada a usos productivos y/o de servicios), que permite un crecimiento urbano discontinuo.

Por último, encontramos otras formas de ocupación irregular, como la edificación residencial sobre loteos "brujos" (parcelaciones ilegales), y la toma irregular de terrenos sobre las que se establecen los campamentos de infravivienda.

\section{Tendencias desreguladoras del suelo no urbanizable en Espańa}

El periodo abierto por la LRSv de 1998 fue el de mayor transformación urbanística en la historia reciente de España. Como muestra quedan los registros del Ministerio de Fomento sobre la concesión de licencias para edificación de viviendas, que alcanzaron valores máximos en el año 2006 (737.186 licencias concedidas) y tras el estallido de la burbuja inmobiliaria han caído algo más de un $95 \%$. A pesar del brusco final de este ciclo especulativo, la influencia de este marco legal sobre el urbanismo español sigue presente, pues sus postulados fueron trasladados a buena parte de los marcos regulatorios del urbanismo en las CC.AA. De hecho, el legislador estatal, consciente de sus límites competenciales, reclama en la exposición de motivos de la citada ley estatal que los legisladores autonómicos extiendan a sus territorios, por la vía de nuevos marcos legales, los principios liberalizadores.

Si tenemos en cuenta la legislación vigente en materia de suelo en España, el Real Decreto Legislativo 7/2015, de 30 de octubre, por el que se aprueba el texto refundido de la Ley de Suelo y Rehabilitación Urbana, existen dos situaciones básicas de suelo: el suelo rural y el suelo urbanizado. Sin embargo, las leyes urbanísticas autonómicas establecen una triple división del suelo (heredada desde la Ley del Suelo de 1956 y presente en todos los cuerpos legales estatales), que de forma sintética y aun adoptando distintas nomenclaturas es la siguiente: suelo no urbanizable (sNU categorizado en común y protegido), suelo urbanizable y suelo urbano. ${ }^{5}$

No obstante, esta clasificación adquiere una concreción espacial a través del planeamiento urbanístico, por lo que la ausencia del mismo o la vigencia de algunos instrumentos sin capacidad para establecer esta triple división (Proyectos de Delimitación de Suelo Urbano) se constituyen como impedimentos para formar un desarrollo urbano ordenado. De hecho, un tercio de los municipios espańoles carece de planeamiento $(18,14 \%)$ o tiene vigente una figura que no permite la existencia de suelo urbanizable ni la categorización del SNU (14,98\%). Ante esto, algunas CC.AA. han optado por categorizar como protegido todo el SNU de los municipios sin planeamiento, o de aquellos sin posibilidad de categorizar esta clase de suelo, como forma de salvaguardar estos espacios del crecimiento urbanístico irregular. ${ }^{6}$ Esta casuística se halla en comunidades como Cantabria (aunque admite edificabilidad a través de la figura de los Planes Especiales de Suelo Rústico), Comunidad Valenciana, Islas Canarias (categorizado como de protección territorial) y Región de Murcia. En el resto de CC.AA. la categorización se asemeja al sNu común, con algunas

5 Si establecemos una correspondencia entre las clases urbanísticas de suelo establecidas por la legislación autonómica y las situaciones básicas de suelo establecidas por la legislación estatal, se debería incluir dentro de la situación de suelo rural las clases de sNu y suelo urbanizable, y dentro de la situación de suelo urbanizado, la clase de suelo urbano.

6 No existe prescripción a nivel administrativo de los delitos urbanísticos sobre sNu protegido. 
particularidades, como en Castilla-La Mancha y Castilla y León, donde se puede categorizar el SNU incluso sin planeamiento urbanístico, gracias a la incorporación directa a la división urbanística del suelo de aquellas zonificaciones provenientes de la planificación territorial o de las afecciones sectoriales.

La expansión residencial irregular en España sobre snu, lejos de encontrar confrontación, ha disfrutado de mayor cabida dentro del ordenamiento jurídico por la vía de la innovación y la modificación legislativa. Los gobiernos autonómicos han articulado esta normalización de la expansión urbana a través de tres acciones principales:

a. Desregulación/flexibilización del SNU: desde la promulgación de sus marcos legales, las CC.AA. han aumentado la capacidad de acogida para uso residencial de esta clase de suelo.

b. Instrumentalización: los gobiernos regionales han promovido la creación de instrumentos de orden jerárquico superior al planeamiento urbanístico destinados a facilitar, entre otros usos, el establecimiento de viviendas sobre SNU.

c. Legalización y amnistía: aquellas regiones donde la urbanización ilegal y clandestina ha alcanzado una magnitud de inabarcable gestión y difícil resolución, se ha optado por iniciar procesos de regularización, y en los casos más extremos se ha procedido a iniciar una amnistía condicionada de viviendas irregulares a través de leyes y decretos ad hoc.

La primera de las acciones que han facilitado la dispersión del uso residencial fuera de los núcleos urbanos ha sido la flexibilización de los estándares urbanísticos en el SNU. Durante las últimas dos décadas se observa una tendencia hacia la desregulación que experimenta avances y retrocesos. Entre las medidas tendentes a la ampliación del aprovechamiento urbanístico está la creación de categorías de suelo específicas para la implantación de viviendas unifamiliares en el medio rural, asentadas sobre la legislación autonómica (la norma urbanística de Aragón contempla unas "zonas de borde" con mayor capacidad de carga del uso residencial en los espacios periféricos de los pequeños municipios) o sobre el planeamiento urbanístico (varios municipios extremeños incluyen categorías con tolerancia residencial en el SNU), que han venido acompañadas de una reducción del tamaño mínimo de la parcela edificable.

En sentido contrario, y como ejemplo paradigmático de un infrecuente proceso, se encuentra la revocación de la Ley 5/2012, de 20 de diciembre, de Viviendas Rurales Sostenibles de la Comunidad de Madrid, tras poco más de 1.200 días de vigencia. Este cuerpo legal permitió la edificación de viviendas en parcelas con una superficie igual o superior a 6 hectáreas sin sometimiento a procedimientos de vigilancia ambiental, sin control supramunicipal y beneficiadas de un silencio administrativo positivo para el otorgamiento de licencias.

En segundo término, el establecimiento de instrumentos territoriales con carácter ejecutivo ha sido una de las vías utilizadas para la implantación del uso residencial en SNU. De hecho, nueve de las diecisiete CC.AA. (Aragón, Cantabria, Castilla-La Mancha, Castilla y León, Extremadura, Galicia, La Rioja, Murcia y Navarra) contienen en sus marcos legales instrumentos que posibilitan la existencia 
de viviendas en el SNU, bajo la argumentación de un interés regional/social que se fundamenta en el derecho a la vivienda reconocido en la Constitución Española de 1978. La prevalencia de la ordenación territorial sobre la urbanística ha provocado desajustes entre ambas, imponiendo proyectos puntuales sobre un espacio previamente planeado espacial y temporalmente (Jiménez \& Campesino, 2016), en el que las zonas destinadas al crecimiento urbano (suelo urbanizable) no han sido colmatadas, mientras se da aprovechamiento urbanístico a secciones del sNU. Junto con estos instrumentos, existen otros más específicos, como los Planes Especiales de Suelo Rústico en Cantabria. Estos permiten, aun en ausencia de planeamiento urbanístico municipal, la aparición del uso residencial, siempre y cuando se localice en entornos cercanos al suelo urbano, medida destinada a paliar la dispersión de viviendas.

En tercer lugar, todas las CC.AA. han formado los parámetros para regularizar las actuaciones ilegales o clandestinas (tabla 2). De esta forma, se propone un reconocimiento de la situación jurídica de las edificaciones sobre la base del respeto de los principios de igualdad, equidad, proporcionalidad y legalidad. Ante la imposibilidad de respetar estos principios, pero situándose dentro de unos límites fijados por las normas, se han establecido modelos de asimilación de las edificaciones al régimen de fuera de ordenación. Esto significa que estas viviendas podrán seguir existiendo, aunque no podrán ser ampliadas, sino simplemente restauradas o mejoradas.

Entre las iniciativas destinadas al control del problema está la confección de catálogos de edificaciones que no cumplan las exigencias que fija la norma. Sus objetivos son iniciar procesos de legalización o, previa denuncia ante los tribunales, asignar medidas punitivas como la imposición de multas o la ejecución de demoliciones. Sin embargo, solo Canarias y Aragón (catálogo de parcelaciones ilegales) contienen esta exigencia en sus legislaciones, mientras que Andalucía ha optado por adjuntar delimitaciones de asentamientos urbanísticos en el SNU, en lugar de un recuento de edificaciones aisladas, al planeamiento municipal. Otras CC.AA., como Cantabria, Cataluña y Asturias, contemplan la posibilidad de elaborar catálogos, pero solo para registrar aquellos núcleos rurales tradicionales o edificaciones implantadas en el medio rural que mantengan los valores tradicionales y el respeto paisajístico.

Por último, en algunas CC.AA. los procesos de amnistía de viviendas irregulares sobre SNU han indultado todo el crecimiento residencial sobre SNU anterior a la entrada en vigor de la Ley estatal 19/1975, de 2 de mayo, de reforma de la Ley sobre el Régimen del Suelo y Ordenación Urbana. Según el legislador andaluz (Junta de Andalucía, 2012), antecesor de otros como el valenciano (Comunitat Valenciana, 2014) y el extremeńo (Junta de Extremadura, 2015), se toma esta fecha "por ser esta Ley la que estableció el régimen de licencia para las edificaciones en SNU que persiste en la actualidad". No obstante, se han impulsado otras iniciativas, como la del Govern de las Islas Baleares (2014), hoy derogada mediante decreto (2016), para la amnistía de viviendas construidas en SNU con más de ocho años de antigüedad, tomando como referencia los plazos de prescripción contenidos en su legislación específica. 
TABLA 2 Corpus legal urbanístico autonómico destinado a la regularización de viviendas en SNU

\begin{tabular}{|c|c|}
\hline $\begin{array}{l}\text { COMUNIDAD } \\
\text { AUTÓNOMA }\end{array}$ & TEXTO NORMATIVO PARA LA REGULARIZACIÓN DE VIVIENDAS EN EL SNU \\
\hline Andalucía & $\begin{array}{l}\text { Decreto 2/2012, de } 10 \text { de enero, por el que se regula el régimen de las edificaciones y } \\
\text { asentamientos existentes en el SNU en la Comunidad Autónoma de Andalucía. } \\
\text { Ley } 6 / 2016 \text {, de } 1 \text { de agosto, por la que se modifica la Ley } 7 / 2002 \text {, de } 17 \text { de diciembre, } \\
\text { de Ordenación Urbanística de Andalucía para incorporar medidas urgentes en relación } \\
\text { con las edificaciones construidas sobre parcelaciones urbanísticas en SNU. }\end{array}$ \\
\hline Aragón & $\begin{array}{l}\text { Decreto Legislativo 1/2014, de } 8 \text { de julio, del Gobierno de Aragón, por el que se } \\
\text { aprueba el texto refundido de la Ley de Urbanismo de Aragón. Título V, Capitulo IV, } \\
\text { Sección II: Regularización de parcelaciones ilegales. }\end{array}$ \\
\hline Asturias & $\begin{array}{l}\text { Decreto Legislativo } 1 / 2004 \text {, de } 22 \text { de abril, por el que se aprueba el texto refundido de } \\
\text { las disposiciones legales vigentes en materia de ordenación del territorio y urbanismo. } \\
\text { Artículo 240: Legalización de obras sin licencia. }\end{array}$ \\
\hline Baleares & $\begin{array}{l}\text { Ley } 2 / 2014 \text {, de } 25 \text { de marzo, de ordenación y uso del suelo. Título viI, Capítulo V, } \\
\text { Sección II: El restablecimiento del orden jurídico perturbado y la reposición de la } \\
\text { realidad física alterada. }\end{array}$ \\
\hline Canarias & $\begin{array}{l}\text { Decreto } 11 / 1997 \text {, de } 31 \text { de enero, por el que se regula la constitución de un censo } \\
\text { de edificaciones no amparadas por licencia y por el que se establecen los supuestos de } \\
\text { suspensión de la ejecutoriedad de las órdenes de demolición. }\end{array}$ \\
\hline Cantabria & $\begin{array}{l}\text { Ley } 2 / 2001 \text {, de } 25 \text { de junio, de Ordenación Territorial y Régimen Urbanístico del } \\
\text { Suelo de Cantabria. Disposición adicional quinta: Normativa aplicable a los Planes } \\
\text { Especiales de Suelo Rústico y los Catálogos de Edificaciones en Suelo Rústico. }\end{array}$ \\
\hline $\begin{array}{l}\text { Castilla y } \\
\text { León }\end{array}$ & $\begin{array}{l}\text { Ley 5/1999, de } 8 \text { de abril, de Urbanismo de Castilla y León. Modificada por Ley } \\
\text { 7/2014, de } 12 \text { de septiembre, de medidas sobre rehabilitación, regeneración y reno- } \\
\text { vación urbana, y sobre sostenibilidad, coordinación y simplificación en materia de } \\
\text { urbanismo. Disposición adicional décima: Asentamientos irregulares. }\end{array}$ \\
\hline $\begin{array}{l}\text { Castilla-La } \\
\text { Mancha }\end{array}$ & $\begin{array}{l}\text { Decreto Legislativo } 1 / 2010 \text {, de } 18 \text { de mayo, por el que se aprueba el texto refundido } \\
\text { de la Ley de Ordenación del Territorio y de la Actividad Urbanística. Artículo 178: El } \\
\text { régimen de legalización de las actuaciones clandestinas. } \\
\text { Decreto 34/2011, de } 26 \text { de abril, por el que se aprueba el Reglamento de Disciplina } \\
\text { Urbanística del Texto Refundido de la Ley de Ordenación del Territorio y de la Activi- } \\
\text { dad Urbanística. Título V, Capítulo I, Sección I: De la legalización de las actuaciones } \\
\text { clandestinas o ilegales. }\end{array}$ \\
\hline Cataluña & $\begin{array}{l}\text { Ley } 3 / 2009 \text {, de } 10 \text { de marzo, de regularización y mejora de urbanizaciones con déficits } \\
\text { urbanísticos. }\end{array}$ \\
\hline $\begin{array}{l}\text { Comunidad } \\
\text { de Madrid }\end{array}$ & $\begin{array}{l}\text { Ley 9/2001, de } 17 \text { de julio, del Suelo, de la Comunidad de Madrid. Artículo 194: } \\
\text { Legalización de actos de edificación o uso del suelo en curso de ejecución. }\end{array}$ \\
\hline $\begin{array}{l}\text { Comunidad } \\
\text { Foral de } \\
\text { Navarra }\end{array}$ & $\begin{array}{l}\text { Ley Foral 35/2002, de } 20 \text { de diciembre, de Ordenación del Territorio y Urbanismo. } \\
\text { Artículo 149: Reparcelación. }\end{array}$ \\
\hline $\begin{array}{l}\text { Comunitat } \\
\text { Valenciana }\end{array}$ & $\begin{array}{l}\text { Ley 5/2014, de } 25 \text { de julio, de Ordenación del Territorio, Urbanismo y Paisaje, de la } \\
\text { Comunitat Valenciana. } \\
\text { Disposición final segunda: Situación de determinadas edificaciones aisladas sin licencia. } \\
\text { Artículo 210: Actuaciones de minimización del impacto territorial generado por los } \\
\text { núcleos de viviendas en el suelo no urbanizable. }\end{array}$ \\
\hline
\end{tabular}


(continuación)

\begin{tabular}{|c|c|}
\hline $\begin{array}{l}\text { COMUNIDAD } \\
\text { AUTÓNOMA }\end{array}$ & TEXTO NORMATIVO PARA LA REGULARIZACIÓN DE VIVIENDAS EN EL SNU \\
\hline Extremadura & $\begin{array}{l}\text { Ley 15/2001, de } 14 \text { de diciembre, del Suelo y Ordenación Territorial de Extremadura. } \\
\text { Disposición adicional séptima: Edificaciones anteriores a la Ley 19/1975, de } 2 \text { de } \\
\text { mayo, de Reforma de la Ley del Suelo y Ordenación Urbana. } \\
\text { Artículo 193: Régimen de legalización de las actuaciones clandestinas. } \\
\text { Disposición adicional quinta: Regularización de actuaciones clandestinas o ilegales de } \\
\text { carácter aislado que forman núcleo de población. }\end{array}$ \\
\hline Galicia & $\begin{array}{l}\text { Ley } 2 / 2016 \text {, de } 10 \text { de febrero, del suelo de Galicia. Disposición transitoria séptima: } \\
\text { Asentamientos surgidos al margen del planeamiento. }\end{array}$ \\
\hline La Rioja & $\begin{array}{l}\text { Ley 5/2006, de } 2 \text { de mayo, de Ordenación del Territorio y Urbanismo de La Rioja. } \\
\text { Capítulo IV: Planes especiales de regularización urbanística. }\end{array}$ \\
\hline País Vasco & $\begin{array}{l}\text { Ley } 2 / 2006 \text {, de } 30 \text { de junio, de Suelo y Urbanismo. Artículo 221: Régimen de legaliza- } \\
\text { ción de las actuaciones clandestinas. } \\
\text { Decreto } 105 / 2008 \text {, de } 3 \text { de junio, de medidas urgentes en desarrollo de la Ley 2/2006, } \\
\text { de } 30 \text { de junio, de Suelo y Urbanismo. Artículo 8: Procedimiento de delimitación y } \\
\text { regularización de fincas en suelo de núcleo rural. }\end{array}$ \\
\hline $\begin{array}{l}\text { Región de } \\
\text { Murcia }\end{array}$ & $\begin{array}{l}\text { Ley } 13 / 2015 \text {, de } 30 \text { de marzo, de ordenación territorial y urbanística de la Región de } \\
\text { Murcia. Artículo 276: Restablecimiento de la legalidad en edificaciones y parcelaciones. }\end{array}$ \\
\hline
\end{tabular}

\section{Conclusiones}

Los Estados neoliberales han desplegado un grupo de políticas, proyectos e instrumentos urbanísticos, o con incidencia en el urbanismo, destinados a normalizar la transición desde un paradigma de ciudad compacta hasta un prototipo de ciudad difusa y fragmentada que ha ocupado progresivamente espacios que no le son propios, redundando así en un desarrollo urbano insostenible, al servicio del mercado inmobiliario y alejado del interés social.

El estudio de los cuerpos normativos de Chile y España nos permite constatar dos situaciones disímiles en cuanto al grado de implantación de este modelo. Si bien en Chile la expresión espacial de las políticas neoliberales encontró cumplimiento desde principios de la década de los ochenta, en España las políticas liberalizadoras de suelo fueron iniciadas mediada la década de los noventa. Además, el reparto competencial urbanístico español entre sus cC.AA. también influye, pues dificulta el establecimiento de medidas que repercutan en el territorio nacional al unísono, algo que es factible en Chile gracias a un Estado centralizado. A pesar de esto, si bien no se puede afirmar un grado homogéneo en cuanto a la aplicación de medidas desreguladoras en España, sí hay una clara tendencia hacia este hecho influenciada por la LRSV.

La regulación de capacidad de carga con respecto al uso residencial de los terrenos rurales presenta importantes déficits en la legislación chilena desde su promulgación, mientras que en Espańa se mantiene una amplia cobertura normativa del sNU, aunque esta producción legislativa no significa una mejora en la protección del mismo, sino todo lo contrario.

La conceptualización de los terrenos rurales como espacio residual y de reserva urbana queda registrada de forma notoria en la LGUC chilena. La legislación ubica los terrenos rurales en una posición subalterna con respecto a las zonas urbanas. En 
el caso español, el modelo está basado en la zonificación del territorio municipal, dirigiendo de manera ordenada y autolimitada el desarrollo inmobiliario sobre espacios localizados y dimensionados en función de las necesidades, facilitando la distinción entre las zonas urbanas actuales, futuras y vedadas al desarrollo urbanístico. A pesar de esto, el concepto de SNU surge como contraposición al suelo urbano y urbanizable en la legislación urbanística de las regiones españolas, situándolo, al igual que en Chile, en una posición subordinada (especialmente al SNU común).

El neoliberalismo ha consolidado su ideología a través de políticas urbanas, entre otros medios, que se han plasmado en nuevas legislaciones al servicio de una producción inmobiliaria que ahora fija como objetivo los espacios exteriores al límite urbano. En el presente estudio, se muestra que las estrategias que comparten ambos países tienden a facilitar la integración del concepto de valor de cambio en los espacios rurales, entendido este dentro de un contexto urbanístico. Para culminar este proceso, ambos Estados han provisto a los agentes urbanísticos de la base legal e instrumental para incluir estos espacios en el mercado inmobiliario. El espacio rural se convierte en un nuevo ámbito geográfico donde generar plusvalías y multiplicar rentas.

Tanto en Chile como en España, el proceso parte de la minimización de los estándares requeridos para construir viviendas en los terrenos rurales/suelo no urbanizable. La reducción del tamaño predial mínimo edificable contribuye al logro de la casa propia bajo las apetencias actuales de contacto con la naturaleza (oportunamente valorizado por los comerciales inmobiliarios) de una clase media con una capacidad de desplazamiento optimizada por el uso del transporte privado. La extensión de esta medida a toda la jurisdicción comunal/municipal, a excepción de los espacios protegidos sectorialmente, promueve los desarrollos inconexos. Consecuentemente, se fomenta un modelo tendente a la construcción de ciudad bajo parámetros de escasa densidad edificatoria y demográfica, lo que implica una mayor insostenibilidad del sistema, al requerir este de mayores recursos para menos habitantes.

El proceso continúa en ambos países con la instrumentalización del proceso. La creación de instrumentos de planificación para la implantación de usos residenciales ha fomentado la oferta agrupada de viviendas en entornos rurales. El mercado inmobiliario se instala de forma compacta, colectiva y vertiginosa en contextos rurales, gozando además de amparo legal. La legitimación del proceso y la implicación de la propia administración multiplican la demanda de este tipo de desarrollos y dificultan la oposición a ellos, relegada a grupos de presión minoritarios, como los ecologistas.

En último lugar, cabe hacer una diferenciación entre estos dos países. Mientras en Chile la capacidad de los terrenos rurales para absorber crecimientos urbanísticos estaba plenamente instalada en su legislación, en España no estaba extendida. La realidad fáctica ha obligado a los gobiernos autonómicos a iniciar procesos de legalización del crecimiento irregular sobre sNu. Tales procesos ocurren bajo la fórmula de la aceptación previa de las cargas urbanísticas por parte de los propietarios, incluyendo penalizaciones, para el posterior acceso a los beneficios, como la inclusión en las redes de servicios públicos y el reconocimiento legal de la propiedad de la vivienda. Con todo, el sistema ha fracasado por la concurrencia de dos hechos: por 
un lado, la lentitud de la administración ha mermado su capacidad de imponer sanciones por la prescripción de los delitos; y, por otro lado, la legalización de lo edificado no se hace imprescindible para el acceso a los servicios, ya que estos se han conseguido de manera autónoma (pozos, generadores eléctricos) o alegal (justificada por la presencia de usos agrarios).

Así, el modelo chileno dota de los instrumentos necesarios a los agentes urbanísticos para promover legalmente la implantación residencial en prácticamente cualquier ámbito territorial, mientras que el español restringe usos y espacios, dirigiendo sus esfuerzos a promover un modelo compacto. Sin embargo, si analizamos el resultado práctico, en ambos países encontramos dentro del mundo rural expresiones análogas en cuanto al uso, tipo y densidad de la edificación, que en el país sudamericano se integran en su cuerpo legal, mientras que en Espańa tienen la consideración de actuaciones ilegales y clandestinas. Así, las restricciones preliminares en el país europeo se tornan contraproducentes al no ir acompañadas de un control de la disciplina urbanística y, en último término, por la escasa aplicación de medidas sancionadoras.

TABLA 3 Anexo explicativo con la normativa citada en el texto

\begin{tabular}{|c|c|c|c|}
\hline AÑo & $\begin{array}{l}\text { CUERPO NORMATIVO O } \\
\text { PLANEAMIENTO }\end{array}$ & PAÍS & DESCRIPCIÓN \\
\hline 1956 & $\begin{array}{l}\text { Ley sobre el Régimen del Suelo y } \\
\text { Ordenación Urbana. }\end{array}$ & España & $\begin{array}{l}\text { Normativa estatal de suelo (primera a nivel } \\
\text { nacional). }\end{array}$ \\
\hline 1965 & $\begin{array}{l}\text { Plan Regulador Metropolitano de } \\
\text { Valparaíso. }\end{array}$ & Chile & Instrumento de planeamiento urbano. \\
\hline 1974 & Decreto Ley n ${ }^{\circ} 752$, de 1974. & Chile & Normas sobre división de predios rústicos. \\
\hline 1975 & Decreto con Fuerza de Ley no 458. & Chile & $\begin{array}{l}\text { Normativa estatal de urbanismo } \\
\text { (Ley General de Urbanismo y } \\
\text { Construcciones de Chile). }\end{array}$ \\
\hline 1975 & $\begin{array}{l}\text { Ley estatal 19/1975 de reforma de la Ley } \\
\text { sobre el Régimen del Suelo y Ordenación } \\
\text { Urbana. }\end{array}$ & España & $\begin{array}{l}\text { Normativa estatal de suelo (reforma la } \\
\text { anterior). }\end{array}$ \\
\hline 1979 & Política Nacional de Desarrollo Urbano. & Chile & $\begin{array}{l}\text { Directrices para el desarrollo urbano } \\
\text { nacional (no vinculantes). }\end{array}$ \\
\hline 1979 & Decreto Supremo no 420 & Chile & $\begin{array}{l}\text { Modificación del Plan Regulador } \\
\text { Intercomunal de Santiago de } 1960 \\
\text { (primera flexibilización del uso urbanístico } \\
\text { de los terrenos rurales). }\end{array}$ \\
\hline 1980 & Decreto Ley no 3.516. & Chile & $\begin{array}{l}\text { Ley agraria que afecta a las normas sobre } \\
\text { división de predios rústicos al reducir el } \\
\text { tamańo mínimo de las mismas. }\end{array}$ \\
\hline 1985 & Política Nacional de Desarrollo Urbano. & Chile & $\begin{array}{l}\text { Directrices para el desarrollo urbano } \\
\text { nacional (no vinculantes). }\end{array}$ \\
\hline 1992 & Decreto Supremo n ${ }^{\circ} 47$. & Chile & $\begin{array}{l}\text { Ordenanza General de Urbanismo y } \\
\text { Construcciones de Chile. }\end{array}$ \\
\hline
\end{tabular}


(continuación)

\begin{tabular}{|c|c|c|c|}
\hline AÑo & $\begin{array}{l}\text { CUERPO NORMATIVO O } \\
\text { PLANEAMIENTO }\end{array}$ & PAÍS & DESCRIPCIÓN \\
\hline 1994 & $\begin{array}{l}\text { Ley } n^{\circ} 19.300 \text {, sobre Bases Generales del } \\
\text { Medio Ambiente. }\end{array}$ & Chile & $\begin{array}{l}\text { Introducción de la obligada aplicación de } \\
\text { la Evaluación Ambiental Estratégica a los } \\
\text { instrumentos de planificación. }\end{array}$ \\
\hline 1994 & Plan Regulador Metropolitano de Santiago. & Chile & Instrumento de planeamiento urbano. \\
\hline 1997 & $\begin{array}{l}\text { Ley } 7 / 1997 \text { de medidas liberalizadoras en } \\
\text { materia de suelo y de colegios } \\
\text { profesionales. }\end{array}$ & Espańa & $\begin{array}{l}\text { Normativa precursora de la liberalización } \\
\text { del suelo en España. }\end{array}$ \\
\hline 1998 & $\begin{array}{l}\text { Ley 6/1998 de Régimen del Suelo y } \\
\text { Valoraciones. }\end{array}$ & España & $\begin{array}{l}\text { Ley estatal de suelo (principal desencade- } \\
\text { nante normativo de la burbuja inmobiliaria } \\
\text { espańola por la flexibilización del suelo). }\end{array}$ \\
\hline 1998 & $\begin{array}{l}\text { Ley } \mathrm{n}^{\circ} 19.537 \text { sobre copropiedad } \\
\text { inmobiliaria. }\end{array}$ & Chile & $\begin{array}{l}\text { Normativa que regula los condominios de } \\
\text { viviendas. }\end{array}$ \\
\hline 1998 & Decreto Supremo no 46. & Chile & Reglamento de la Ley no 19.537. \\
\hline 2000 & $\begin{array}{l}\text { Decreto Supremo de Vivienda y } \\
\text { Urbanismo no } 259 \text {. }\end{array}$ & Chile & Normativa que deroga el PNDU de 1985. \\
\hline 2003 & Ley no 19.859. & Chile & $\begin{array}{l}\text { Normativa para la construcción de viviendas } \\
\text { con subsidio en terrenos rurales. }\end{array}$ \\
\hline 2012 & $\begin{array}{l}\text { Ley 5/2012 de Viviendas Rurales } \\
\text { Sostenibles de la Comunidad de Madrid. }\end{array}$ & Espańa & $\begin{array}{l}\text { Normativa autonómica de suelo de carácter } \\
\text { flexibilizador (derogada). }\end{array}$ \\
\hline 2013 & Política Nacional de Desarrollo Urbano. & Chile & $\begin{array}{l}\text { Directrices para el desarrollo urbano } \\
\text { nacional (no vinculantes). }\end{array}$ \\
\hline 2014 & $\begin{array}{l}\text { Ley } 2 / 2014 \text {, de } 25 \text { de marzo, de ordenación } \\
\text { y uso del suelo del Govern de las Islas } \\
\text { Baleares. }\end{array}$ & España & $\begin{array}{l}\text { Primera legislación del suelo de la } \\
\text { Comunidad Autónoma de las Islas Baleares. }\end{array}$ \\
\hline 2015 & $\begin{array}{l}\text { Real Decreto Legislativo } 7 / 2015 \text {, por el } \\
\text { que se aprueba el texto refundido de la Ley } \\
\text { de Suelo y Rehabilitación Urbana. }\end{array}$ & Espańa & Normativa estatal de suelo (vigente). \\
\hline 2016 & $\begin{array}{l}\text { Decreto Ley } 1 / 2016 \text {, de } 12 \text { de enero, de } \\
\text { medidas urgentes en materia urbanística } \\
\text { del Govern de las Islas Baleares. }\end{array}$ & España & $\begin{array}{l}\text { Derogación de la amnistía para viviendas } \\
\text { ilegales incluida en la Ley } 2 / 2014 \text {. }\end{array}$ \\
\hline
\end{tabular}

FUENTE ELABORACión PROPIA

En resumen, queda constatada la existencia de políticas neoliberales destinadas a potenciar la expansión urbana sobre lo rural, y a apoyar un modelo difuso en detrimento de uno compacto. En Espańa, el esquema garantista renuncia a la regulación de los crecimientos dispersos, pero la elusión del problema no significa su inexistencia, pues se produce fuera del sistema. La indisciplina urbanística, construida a partir de decisiones individuales y promociones colectivas, unida a la inacción de los gobiernos competentes, magnifica la dispersión residencial de primera y segunda residencia. Mientras Espańa ignoró este fenómeno en su normativa hasta que el problema careció de solución por su magnitud, Chile potenció sin complejos este modelo como forma de crecimiento urbano, apostando por una disociación clara entre la aptitud urbanística del espacio y la legitimación justificada del desarrollo urbano. Ahora, ambos países caminan hacia la confluencia sobre un modelo único que genera un consumo improductivo del territorio. 


\section{Agradecimientos}

Esta investigación está financiada por el Ministerio de Educación, Cultura y Deporte, a través del Programa de Formación del Profesorado Universitario (FPU). Referencia FPUi 3/oo99o.

De igual modo, la financiación proviene del Fondecyt regular de investigación 1150360, "La política de vivienda social en las áreas metropolitanas de Santiago y Valparaíso: entre la desigualdad y la sostenibilidad del desarrollo urbano (1992-2014)".

\section{Referencias bibliográficas}

AA.Vv. (2006). Manifiesto por una nueva cultura del territorio. http://www.ehu.eus/Jmoreno/ ArchivosPOT/manifiesto.pdf

Augé, M. (1992). Non-lieux. Introduction á une anthropologie de la surmodenité. París: Édition du Seuil.

Berry, B. J. L. (1976). Urbanization and counterurbanization. Beverly Hills, CA: Sage Publications.

Brieva, A. \& Bastias, L. (1980). Ordenanza General de Construcciones y Urbanización. Santiago de Chile: Editorial Jurídica de Chile.

Burriel, E. L. (2008). La "década prodigiosa” del urbanismo español (1997-2006). En AA.vv., Diez años de cambios en el Mundo, en la Geografía y en las Ciencias Sociales, 1999-2008. Actas del X Coloquio Internacional de Geocritica. Barcelona: Universidad de Barcelona.

Campesino, A.-J. (2003). Planificación y gestión urbana descentralizadas en América Latina. En F. Manero \& L. J. Pastor (coords.), El espacio latinoamericano. Cambio económico y gestión urbana en la era de la globalización (pp. 427-447). Valladolid: Universidad de Valladolid.

Capel, H. (2003). A modo de introducción: Los problemas de las ciudades: urbs, civitas y polis. Mediterráneo Económico, 3, 9-22. http://www.publicacionescajamar.es/pdf/ publicaciones-periodicas/mediterraneo-economico/3/3-18.pdf

Champion, A. G. (1989). Counterurbanization. The changing pace and nature of population desconcentration. Londres: Edward Arnold.

Costes, L. (2011). Del 'derecho a la ciudad' de Henri Lefebvre a la universalidad de la urbanización moderna. Urban, (2), 89-100. http://polired.upm.es/index.php/urban/ article/view/1495/1990

Delgado, C. (2012). Protección y ordenación del medio natural en Cantabria. Normativa, instrumentos y conflictos territoriales. Boletín de la Asociación de Geógrafos Españoles, (60), 115-140. http://www.age-geografia.es/ojs/index.php/bage/article/ viewFile/1501/1421

Delgado, M. (2004). De la ciudad concebida a la ciudad practicada. Archipiélago. Cuadernos de critica de la cultura, (62), 7-12. https://cartografiasurbanas09.files.wordpress. com/2009/08/txt_art_archip_manuel-delgado.pdf 
Dematteis, G. (1998). Suburbanización y periurbanización. Ciudades anglosajonas y ciudades latinas. En F. J. Monclús (ed.), La ciudad dispersa (pp. 17-33). Barcelona: Centre de Cultura Contemporània de Barcelona.

Gaja, F. (2015). Reparar los impactos de la burbuja constructora. Scripta Nova. Revista Electrónica de Geografía y Ciencias Sociales, 19(517). http://www.ub.edu/geocrit/sn/ sn-517.pdf

Generalitat Valenciana. (2014). Ley 5/2014, de 25 de julio. Publicada en Diari Oficial de la Generalitat Valenciana No. 7329, del 31 de julio de 2014. Espańa.

Harvey, D. (2007). Breve historia del neoliberalismo. Barcelona: Editorial Akal.

Henoch, P. \& Horst, B. (2011). Déficit habitacional: se mantiene tendencia al alza. Serie Informe Económico 216. Santiago de Chile: Libertad y Desarrollo. http:// lyd.org/wp-content/themes/LYD/files_mf/sie216deficithabitacionalseman tienelatendencialaalzaphenochybhorstjunio2011.pdf

Hidalgo, R., Arenas, F. \& Santana, D. (2016). ¿Utópolis o distópolis?: producción inmobiliaria y metropolización en el litoral central de Chile (1992-2012). Revista Latinoamericana de Estudios Urbano Regionales, 42(126), 27-54. http://dx.doi.org/10.4067/S025071612016000200002

Indovina, F. (1990). La città diffusa. Venecia: Istituto Universitario di Architettura di Venezia.

Iturriaga, J. (2003). Ordenamiento territorial en Chile: instituciones, instrumentos, problemas y propuestas. Tesis de Maestría, Pontificia Universidad Católica de Chile. http://www. ceh.cl/wp-content/uploads/2009/12/J-Iturriaga-2003.pdf

Jiménez, V. \& Campesino, A.-J. (2016). Proyectos de (dudoso) interés regional. Intromisión en la política municipal de vivienda en Extremadura. Boletín de la Asociación de Geógrafos Españoles, (72), 327-347. http://dx.doi.org/10.21138/bage.2343

Junta de Andalucía. (2012). Decreto 2/2012, de 10 de enero. Publicado en Boletín Oficial de la Junta de Andalucía No. 19, del 30 de enero 2012. España.

Junta de Extremadura. (2015). Ley 10/2015, de 8 de abril. Publicada en Diario Oficial de Extremadura No. 68, del 10 de abril de 2015. España.

Koolhas, R. (2006). La ciudad genérica. Barcelona: Editorial Gustavo Gili.

Le Corbusier, C.-É. J. \& Sert, J. L. (1957). La Charte d'Athènes. Paris: Les Éditions de Minuit.

Lefebvre, H. (1968). Le droit à la ville. París: Editorial Anthropos.

Mansilla, P. (2013). Los instrumentos del desorden: Estado y actores subnacionales en la producción de los espacios periurbanos. Revista Persona y Sociedad, 27(2), 41-68 http://personaysociedad.cl/ojs/index.php/pys/article/view/89/51

Méndez, R. \& Plaza, J. (2016). Crisis inmobiliaria y desahucios hipotecarios en España: una perspectiva geográfica. Boletín de la Asociación de Geógrafos Españoles, (71), 99-127. doi: $10.21138 /$ bage. 2276

Ministerio de Vivienda y Urbanismo (Minvu), Chile. (2004). El déficit habitacional en Chile: Medición de requerimientos de vivienda y su distribución espacial. http://www.minvu.cl/ opensite_20070411164536.aspx

Ministerio de Vivienda y Urbanismo (Minvu), Chile. (2009). Una mirada integral a la calidad de vida y el hábitat residencial en Chile. http://www.minvu.cl/opensite_20070411164536. aspx

Monclús, F. J. (1998). La ciudad dispersa. Barcelona: Centre de Cultura Contemporània de Barcelona. 
Nel.lo, O. (1998). Suburbanización y periurbanización. Ciudades anglosajonas y ciudades latinas. En F. J. Monclús (ed.), La ciudad dispersa (pp. 35-57). Barcelona: Centre de Cultura Contemporània de Barcelona.

Piñero, A. (coord.). (2015). El urbanismo de la no ciudad: los procesos de ocupación irregular en el suelo no urbanizable de Andalucía. Sevilla: Agencia de Obra Pública, Consejería de Fomento y Vivienda de la Junta de Andalucía.

Ravetz, J., Fertner, C. \& Nielsen, T. S. (2013). The dynamics of peri-urbanization. En K. Nilsson, S. Pauleit, S. Bell, C. Aalbers \& T. S. Nielsen (eds.), Peri-urban futures: Scenarios and models for land use change in Europe (pp. 13-44). Berlín: Springer.

Sabatini, F. (2000). Reforma de los mercados de suelo en Santiago, Chile: efectos sobre los precios de la tierra y la segregación residencial. Revista Latinoamericana de Estudios Urbano Regionales, 26(77), 49-80. http://dx.doi.org/10.4067/S0250-71612000007700003

Salazar, A. \& Cox, T. (2014). Accesibilidad y valor de suelo como criterios para una localización racional de vivienda social rural en las comunas de San Bernardo y Calera de Tango, Chile. Revista Instituto de la Vivienda, 29(80), 53-81. doi: 10.4067/S071883582014000100003

Senabre, D. \& Campesino, A.-J. (2005). Territorio y ciudades mediterráneas, fundamentos de la identidad cultural europea. En J. R. Flecha \& C. García (coords.), El Mediterráneo en la Unión Europea ampliada (pp. 143-174). Salamanca: Publicaciones de la Universidad Pontificia de Salamanca.

Sobrino, J. (2003). Rurbanización y localización de las actividades económicas en la región centro del país, 1980-1998. Sociológica, 18(51), 99-127. http://www.redalyc.org/ articulo.oa?id=305026632005

Swyngedouw, E. (2004). Globalisation or 'glocalisation'? Networks, territories and rescaling. Cambridge Review of International Affairs, 17(1), 25-48. http://dx.doi. org/10.1080/0955757042000203632

Terán, F. (1982). Planeamiento urbano en la España contemporánea (1900/1980). Madrid: Alianza Universidad Textos.

Terán, F. (1996). Evolución del planeamiento urbanístico (1846-1996). Ciudad y Territorio. Estudios Territoriales, 28(107-108), 167-184. http://oa.upm.es/11491/1/ evolucionplaneamiento.pdf

Torres, M. (2005). Planeación urbana en Chile. Un producto de la especulación inmobiliaria. Boletin $C F+S$, (29-30). http://habitat.aq.upm.es/boletin/n29/amtor.html

Trivelli, P. (1981). Reflexiones en torno a la Política Nacional de Desarrollo Urbano. Revista Latinoamericana de Estudios Urbano Regionales, 8(22), 43-64. http://www.eure.cl/ index.php/eure/article/view/921/36

Vicuña, M. (2013). El marco regulatorio en el contexto de la gestión empresarialista y la mercantilización del desarrollo urbano del Gran Santiago, Chile. Revista Instituto de la Vivienda, 28(78), 181-219. doi 10.4067/S0718-83582013000200006

Weekley, I. (1988). Rural depopulation and counterurbanisation: a paradox. Area, 20(2), 127134. http://www.jstor.org/stable/20002571?seq=1\#page_scan_tab_contents 